\title{
Second-eye cataract surgery was beneficial in otherwise-healthy patients
}

Laidlaw DA, Harrad RA, Hopper CD, et al. Randomised trial of effectiveness of second eye cataract surgery. Lancet 1998 Sep 19;352:925-9.

\section{Question}

In otherwise healthy patients, can second-eye cataract surgery improve visual symptoms and quality of life?

\section{Design}

Randomised controlled trial with 6-month follow-up.

\section{Setting}

An eye hospital in Bristol, England, United Kingdom.

\section{Patients}

208 patients (median age $76 \%, 62 \%$ women) who were awaiting second-eye cataract surgery, had a unilateral cataract and uncomplicated contralateral pseudophakia with corrected Snellen visual acuity of $\geq 20 / 40$ in the pseudophakic eye, had no visually important ophthaimic pathologic findings, and were able to understand the questionnaire. Follow-up was $92 \%$.

\section{Intervention}

Patients were allocated to second-eye cataract surgery within 6 weeks (expedited surgery group, $n=105$ ) or 7 to 12 months of enrollment (control group, $n=103$ ). Patients were assessed at 6 months (before the control group had surgery).

\section{Commentary}

At first glance, the study by Laidlaw and colleagues may seem to be about a rather perverse question. If it is widely accepted that cataract surgery is an effective intervention in one eye, why does it not automatically follow that it is effective for the other eye? This is an important guestion about the best use of limited tesources, which is relevant to global concerns as well as to more parochial considerations within the National Health Service.

This year, the World Health Organization's global initiative for the elimination of avoidable blindness by the year 2020 will belaunched in Beijing at the congress of the International Association for the Prevention of Blindness. The biggest challenge will be to deal with the

\section{Main autcome measures}

Patient's perspective on treatment (4 items from a questionnaire containing 18 items on symptoms of visual dysfunc tion, 9 items on effect on quality of life, and 3 items on visual function) and visual function, which was assessed with the following tests: binocular LogMAR distance visual acuity and near-reading acuity tests taken at 4 metres, binocular Pelli-Robson contrast sensitivity test, and TNO stereotest and Wirt Fly test for stereoacuity. Secondary outcome measures included generic health status (measured by the Short Form-36) and reading speeds.

\section{Main results}

Analysis was by intention to treat. At 6 months, patients in the control group were more likely than those in the expedited surgery group to report that they had at least some difficulty reading normal print $(P<0.001)$, that their eyesight prevented engaging in activities most or all of the time $(P<0.001)$, that they had below-average overall vision $(P<0.001)$,

Second-eye cataract surgery vs control in otherwise healthy patients*

\begin{tabular}{lcccc}
\hline Outcomes at 6 months & Surgery & Control & RRR (95\% CI) & NNT (CD) \\
\hline Difficulty reading nomal print & $6 \%$ & $35 \%$ & $83 \%(62$ to 92$)$ & $4(3$ to 6$)$ \\
Eyesight prevented most activities & $0 \%$ & $11 \%$ & $100 \%$ & $10(6$ to 2$)$ \\
Below average overall vision & $0 \%$ & $18 \%$ & $100 \%$ & $6(4$ to 10$)$ \\
Eyesight interfered greatly in life & $1 \%$ & $26 \%$ & $96 \%(78$ to 99$)$ & $5(3$ to 7$)$ \\
Stereoacuity worse than 3000-sec arc & $12 \%$ & $70 \%$ & $83 \%(71$ to 90$)$ & $2(2$ to 3$)$ \\
\hline
\end{tabular}

*Abbreviations defined in Glossary; RRR, NNT, and CI calculated from data in article. rapidy growing global backlog of blindness caused by cataract, the world"s primary cause of blindness. Various strategies have been proposed to tackle the backlog, which will need a large fund raising programme and efficient deployment of resources to reach those who need them. A component of the strategy is to weight the outcomes of strrgety in terms of "sight restoration procedures" as opposed to simply the number of cataract operations done. Thus, operations for persons who are bilaterally blind from cataract score more than those for per sons with unilateral cataracts or second-eye cataracts, which do not turn a biend person into a sighted one.

This study elegantly addresses these issues and acts as a counterweight to the clinical and that their eyesight interfered with their everyday lives quite a lot or a great $\operatorname{deal}(P<0.001)$ (Table). Patients who had expedited surgery had better scores than control patients for binochlar distance visual acuity (LogMAR mean score -0.027 vs $0.052, P<0.001$ ), binocular near-reading acuity (LogMAR mean score 0.23 vs $0.27, p<0.003$ ), binocular contrast sensitivity (Pellim-Robson mean score 1.76 vs $1.54, P<0.001$ ), and stereoacuity ( $P<0.001$ ) (Table). Heaith status and reading speeds did not differ between groups.

\section{Conclusion}

In otherwise healthy patients awaiting second-eye cataract surgery, those who received surgery within 6 weeks had better quality of life and higher scores on visual function tests at 6 months than did those who continued to await surgery. Source of fonding: Wellome Thust.

For correspondence: Dr: F.M. Sparow, D2 partment of Opbthalmology, Bristol Eye Hospir tal, University of Bristol, Bristol BSI $2 L X_{1}$ England UK PAX 44-117-928-7325. expediency of the public health approach. If tells us clearly that operating on the second eye leads to additional gains, which are mersurable and important in terms of quality? life and vision. What it cannot do is cont pare the relative gain of fitst-eye surgery the second. This information is needed 10 set priorties for first and second eyes on the lengthening waiting lists in the United King dom. The argument is complex, bur this study is of considerable walue in providn? good evidence on which to build atleastpart of the premise.

$$
\begin{array}{r}
\text { Ricbard Wormald, MB, }, \\
\text { Moorfelds Eye Hop } \\
\text { London, Englond }
\end{array}
$$

Evidence-Based Medicine 